\title{
Avoiding and Alternate Possibilities
}

Ezio Di Nucci (Universität Duisburg-Essen, ezio.dinucci@uni-due.de)

\begin{abstract}
Greg Janzen has recently criticised my defence of Frankfurt's counterexample to the Principle of Alternate Possibilities by arguing that Jones avoids killing Smith in the counterfactual scenario. Janzen's argument consists in introducing a new thought-experiment which is supposed to be analogous to Frankfurt's and where the agent is supposed to avoid A-ing. Here I argue that Janzen's argument fails on two counts, because his new scenario is not analogous to Frankfurt's and because the agent in his new scenario does not avoid A-ing.
\end{abstract}

According to the Principle of Alternate Possibilities (PAP), an agent is morally responsible for A-ing only if she could have done otherwise than A-ing. This plausible principle has been famously challenged by Harry Frankfurt's counterexample (1969), where counterfactual intervener Black will make Jones kill Smith in case Jones does not kill Smith on his own. In case Jones does kill Smith on his own without Black's intervention, Jones is responsible for killing Smith even though Jones could not have done otherwise than kill Smith because in the counterfactual scenario Black would have made him kill Smith. This counterexample should then show that moral responsibility does not depend on the ability to do otherwise, defusing a classic incompatibilist challenge to free will. 
Frankfurt's counterexample has generated an enormous literature, mostly consisting of defences of PAP or of variants on Frankfurt's original scenario. ${ }^{1}$ Within this debate, there is a relatively under-discussed challenge to Frankfurt's counterexample according to which in the counterfactual scenario Jones does not kill Smith (Black does), and therefore in the actual scenario Jones does have an alternative to killing Smith, namely not killing Smith. Following this challenge, then, PAP withstands Frankfurt's counterexample because Jones is responsible for killing Smith in the actual scenario and could have done otherwise than killing Smith - as in the counterfactual scenario Jones does not kill Smith. ${ }^{2}$

I have defended Frankfurt's counterexample against this objection on the grounds that the objection fails to distinguish between not A-ing and avoiding A-ing (and therefore between not killing Smith and avoiding killing Smith): in short, Jones does not kill Smith in the counterfactual scenario but Jones does not avoid killing Smith. ${ }^{3}$ Recently Greg Janzen (2013) has criticised my defence of Frankfurt's counterexample by arguing that Jones does indeed avoid killing Smith in the counterfactual scenario. Janzen's argument consists of introducing a new thought-experiment which is supposed to be analogous to Frankfurt's scenario and where, according to Janzen, the agent can be said not just to have not A-ed but also to have avoided A-ing. Here I argue that Janzen's new scenario fails to show that the agent avoided A-ing, and that therefore my defence of Frankfurt stands.

Here is Janzen's scenario $\left(8^{4}\right)$ :

1 Here is a link to the 884 scholarly articles or books citing Frankfurt's counterexample: http://tinyurl.com/9n87t4l (Google Scholar data, accessed 7.10.12). For an overview of this debate, see Fischer 1999. For a more recent survey, see Levy \& McKenna 2009.

2 Mention of this kind of move against Frankfurt's counterexample can be found at least in the following places: Fischer (1982), Kane (1985), Widerker (1995), Kane (1996), McKenna (1997), Wyma (1997), Otsuka (1998), Fischer (1999), Woodward (2002), Pettit (2005), Steward (2006), Alvarez (2009), Larvor (2010), Di Nucci 2010a, Di Nucci 2011a, and Di Nucci 2011b.

${ }^{3}$ Di Nucci 2010a, Di Nucci 2011a, and Di Nucci $2011 b$.

${ }^{4}$ Page numbers refer to pre-print. 
FRAME: Bert has decided to frame Bart. Bert is a super neuroscientist and he has developed a decision-detecting device. This device, when hooked up to his own brain, makes a beeping noise whenever he makes (or reverses) an important decision. He is in Bart's house with Sally looking for a good place to plant incriminating evidence. Just before planting it, he changes his mind about framing Bart. The device makes its beep. Unbeknown to Bert, Sally, who is also a super neuroscientist, knows that the beeping noise reliably indicates that Bert has made (or reversed) an important decision. As it happens, she wants desperately for Bert to frame Bart, and she's implanted a device in Bert's brain that enables her to remotely control his choices. When she hears the beep, she activates the device and causes Bert to reverse his decision not to frame Bart. Bert plants the evidence and Bart is arrested a few hours later.

Janzen argues that in this scenario Bert does not frame Bart and, more importantly, that in this scenario Bert avoids framing Bart. This latter claim, along with the analogy between FRAME and Frankfurt's scenario, is Janzen's argument against my defence of Frankfurt's counterexample:

Premise 1: FRAME is analogous to Frankfurt's counterexample.

Premise 2: In FRAME, Bert avoids framing Bart.

Conclusion: In Frankfurt's counterexample, Jones avoids killing Smith in the counterfactual scenario. 
By Janzen's own admission, his Premise 1 is false and needs revising, because the beeping noise is not analogous to the facial twitch in Frankfurt's case. ${ }^{5}$ Therefore Janzen proposes that the device also make "a whirring noise whenever Bert makes (or reverses) an important decision, and that Sally reacts on the basis of the whirring noise rather than on the basis of the beeping noise. That the whirring noise isn't up to Bert - we can assume that it is the result of a technical glitch of which he, unlike Sally, is unaware" (8). So FRAME needs reformulating:

FRAME2: Bert has decided to frame Bart. Bert is a super neuroscientist and he has developed a decision-detecting device. This device, when hooked up to his own brain, makes a beeping noise whenever he makes (or reverses) an important decision. [The device also makes a whirring noise whenever Bert makes (or reverses) an important decision. The whirring noise is a result of a technical glitch of which Bert, unlike Sally, is unaware.] He is in Bart's house with Sally looking for a good place to plant incriminating evidence. Just before planting it, he changes his mind about framing Bart. The device makes its beep [and its whirring noise]. Unbeknown to Bert, Sally, who is also a super neuroscientist, knows that the [whirring] noise reliably indicates that Bert has made (or reversed) an important decision. As it happens, she wants desperately for Bert to frame Bart, and she's implanted a device in Bert's brain that enables her to remotely control his choices. When she hears the [whirring noise], she

\footnotetext{
5 "We can imagine that Jones has often confronted the alternatives - A and B-that he now confronts, and that his face has invariably twitched when he was about to decide to do $A$ and never when he was about to decide to do B. Knowing this, and observing the twitch, Black would have a basis for prediction" (Frankfurt 1969, p. 835).
} 
activates the device and causes Bert to reverse his decision not to frame Bart.

Bert plants the evidence and Bart is arrested a few hours later.

According to Janzen, FRAME2 is analogous to Frankfurt's case so that the following revised argument is supposed to undermine my defence:

Premise $1^{*}:$ FRAME2 is analogous to Frankfurt's counterexample.

Premise 2*: In FRAME2, Bert avoids framing Bart.

Conclusion: In Frankfurt's counterexample, Jones avoids killing Smith in the counterfactual scenario.

I will not take issue with the validity of this argument; I will rather show that the argument is not sound on two grounds, as both Premise $1^{*}$ and Premise $2^{*}$ are false. Let us start with the first premise. There is a relevant difference between Frankfurt's case and FRAME2: the whirring noise and the facial twitching may be both involuntary, but they are not equivalent from an action-theoretical point of view. Of the whirring noise, we can say that Bert has unintentionally devised it: Bert has devised it unintentionally because his intention was only to devise the beeping noise. Nonetheless, Bert has devised the whirring noise - namely, the production of the whirring noise was an action of his. On Davidson's classic analysis of action (1980), unintentional actions are still actions because they are intentional under some other description: so that devising the whirring noise is still an action of Bert's because it is intentional under the description 'devising the beeping noise'.

Bert has, on this plausible and widely accepted account of action, intentionally devised the beeping noise and unintentionally devised the whirring noise, and both were actions of 
his. This is not the case with Jones's facial twitch: the facial twitch is neither an action, intentional or unintentional, nor is it the result of an action: Jones does not do anything that unintentionally or involuntarily results in the facial twitch in the way in which Bert does something intentionally which unintentionally or involuntarily results in the whirring noise even though as we have seen the twitch is reliably linked, in Frankfurt's original, to the way in which Jones is about to decide.

Janzen's case would have been analogous to a different version of Frankfurt's counterexample in which in the counterfactual scenario Jones decides or attempts to decide not to kill Smith, Jones's decision or attempt causes his face to involuntarily twitch, and the facial twitch alerts Black to the fact that he needs to intervene. On a plausible agential interpretation of decisions or attempts, such a version of Frankfurt's counterfactual scenario would be analogous to Janzen's scenario. But Frankfurt's original counterfactual scenario is importantly different from the variant that would be analogous to Janzen's scenario in that in Frankfurt's original counterfactual scenario there is no decision (or attempt to decide) not to kill Smith and there is no intentional action of Jones which causes his face to twitch and Black to intervene.

Janzen's strategy against Frankfurt's counterexample is to trace agency further back to what brings about the prior sign: a decision not to kill, or an attempted decision not to kill, or even just the sort of deliberation that may result in a decision not to kill. But the problem with Janzen's strategy is, pretty simply, that one need not suppose that the prior sign be brought about by an agential event: it may be brought about by a further non-agential event or even no event at all - given Black's very special powers.

So Premise $1^{*}$ is false because Frankfurt's case and Janzen's are not analogous. Let me say that the difference that we have just identified is crucial to the question of whether 
Jones and Bert can be said to have avoided killing Smith and framing Bart respectively, as we now have a plausible explanation of why in the case of Bert one may have the intuition that Bert avoided framing Bart while in the case of Jones one does not have the intuition that Jones avoided killing Smith: that Bert does not frame Bart is the result of an intentional action of Bert while that Jones does not kill Smith is not the result of an intentional action of Jones.

Furthermore, surely that in Janzen's example Bert actively “changes his mind about framing Bart" (8) while in Frankfurt's counterfactual scenario there is no such change of mind may well make the decisive difference to the relevant intuitions, if one were to have the intuition that Bert avoids framing Bart.

Three points deserve further attention here:

1) it may be argued that even in the absence of an agential event that brings about the facial twitch, we must at least grant that the possibility in the future of such an agential event brings about the facial twitch, as Frankfurt does say that "We can imagine that Jones has often confronted the alternatives - A and B - that he now confronts, and that his face has invariably twitched when he was about to decide to do A and never when he was about to decide to do B. Knowing this, and observing the twitch, Black would have a basis for prediction" (1969: 835). The following counterfactual is relevant here: Jones would have decided not to kill Smith if Black had not intervened to prevent him from deciding not to kill Smith. Even supposing the truth of this counterfactual, is that enough to claim that Jones avoided killing Smith? Shouldn't we rather say that Jones would have avoided killing Smith if Black had not intervened to prevent him from deciding not to kill Smith? After all, we normally don't credit people for things that they did not achieve even though they would 
have possibly achieved them if the world had not unfolded in a way that prevented the achievement.

2) It may be thought that whether or not Black's power of intervention is restricted to his awareness of the twitch will make a difference. Namely, it may be argued that it is one thing if Black or Black's device can only intervene as a result of the twitch; things are different if Black or Black's device could intervene no matter what, then it cannot be that Jones should be said to have avoided killing Smith in the counterfactual scenario only on the very lucky grounds that Black happened to intervene as a result of Jones's facial twitch; what if Black had decided to intervene way earlier just to be on the safe side - then we would not say that Jones avoided killing Smith in the counterfactual scenario.

3) Even having established the disanalogy between the case in which the involuntary prior sign is the result of a decision (Janzen's) and Frankfurt's counterfactual scenario in which the involuntary sign is not the result of a decision, it may be legitimate to wonder what one would make of a Frankfurt-type scenario where the prior sign is the result of a decision. Would in such a case be correct to conclude, with Janzen, that the agent avoids acting? I won't be able to get into much detail here, as this is beyond the scope of my reply to Janzen. But I do want to say a few things about this issue.

It seems to me that avoiding must be intentional, and that that's going to be the difference between not A-ing and avoiding A-ing: the difference being, then, that not A-ing need not be intentional but avoiding A-ing must be intentional. More precisely: if not A-ing is intentional, it just is avoiding A-ing. If not A-ing is not intentional, then it cannot be avoiding A-ing. ${ }^{6}$ The problem, here, for those who would like to argue that Jones's decision to not kill

\footnotetext{
${ }^{6}$ Here one could try to devise cases of unintentional avoidance, such as one in which Lois Lane spends all day Monday actively trying to avoid running into Clark Kent (rescheduling her lunch break, hiding when she hears him coming down the hall, etc.) and she is successful in doing so. Further suppose that she hopes that she will get to see Superman on Monday. Is this a case in which Lois Lane unintentionally avoids running into
} 
Smith will be sufficient for the claim that Jones intentionally brings about the state of affairs in which Jones does not kill Smith (namely, that Jones avoids killing Smith), is that Jones does not act, Black does (that is after all the original insight which motivates the argument Janzen tries to defend): Jones does not bring about the state of affairs in which Jones does not kill Smith - Black brings that state of affairs about: it is Black, after all, who intervenes. The relevant state of affairs - in which Jones does not kill Smith - is brought about by Black's intervention and it is under Black's control and it is only indirectly caused by Jones's decision - and as that causal chain goes through Black's own agency, this wouldn't do even for a causalist about action explanation. ${ }^{7}$

Summing up, I have argued that even in the case in which Jones positively decides not to kill Smith we cannot say that Jones avoids killing Smith. But, importantly, this case is not analogous to Frankfurt's original and there is no need to postulate Jones's positive decision to not kill Smith in order to generate a Frankfurt-type counterexample. So I have made three distinct points against Janzen's argument: (A) there is an important disanalogy between Janzen's case and Frankfurt's case due to the agential character (albeit unintentional) of the whirring noise as opposed to the facial twitch; (B) there is a further major disanalogy between Janzen's case and Frankfurt's due to Bert's positive change of mind in Janzen's case - there is no analogous decision not to kill Smith in Frankfurt's original; (C) finally, even if we

Superman? It is certainly a case in which she didn't intentionally avoid running into Superman. Apart from the peculiarity of "running into" as a passive verb, one could easily claim here that this is a case in which Lois Lane intentionally avoided running into Clark Kent and did not run into Superman (so not A-ing rather avoiding A-ing with regard to 'running into Superman'). One more thing about this case: one may be alternatively tempted to argue that this case points to the need for a more general difference than the one between 'intentionally' avoiding and 'unintentionally' avoiding, namely the one between an agential avoidance and a non-agential avoidance: indeed, this is anyway the direction that talk of not A-ing and avoiding A-ing goes towards and also this is what the distinction between what is up to the agent and what is not up to the agent points to. Thanks to an anonymous referee for this scenario.

${ }^{7}$ A case where one may be able to speak of Jones having avoided killing Smith would be one where Jones knew that his changing his mind would trigger Black's intervention. Even here, though, one will have to distinguish between a scenario where Black's power of intervention is restricted to the event of Jones's changing his mind and a scenario where Black can intervene at will: only the former may be a case of avoiding. 
reformulate Frankfurt's original and insert a decision not to kill Smith on the part of Jones so as to make the case, at least in this respect, analogous to Janzen's, we still do not get the outcome that Janzen needs, namely we don't get the claim that Jones avoids killing Smith even in the scenario in which Jones decides not to kill Smith: this is, in short, because Jones's not killing Smith is brought about by Black, not by Jones.

Having rebutted Premise $1^{*}$ is enough to undermine Janzen's argument; in this respect, my argument against Janzen is complete. But my arguments against Premise $1^{*}$ - especially the last point $(C)$ - have made clear that I think that Premise $2^{*}$ is also false, since I have argued that even in the case in which the agent changes her mind we cannot speak of having avoided the relevant act. Here I would like to add a further consideration against Premise 2*. Janzen's case for the claim that Bert avoided framing Bart in FRAME2 is motivated by the thought that "Sally would not have been able to manipulate him into reversing his decision not to frame Bart if he hadn't conceived, built, had in his possession, etc. the device that alerted her to his decision" (8). Furthermore, Janzen claims that Bert "is responsible for not framing him [Bart]" (9). So there are actually two claims here: Bert avoided framing Bart and Bert is responsible for not framing Bart, with the latter claim supposedly motivating and illustrating the former. But this is too strong: if an event $E$ is not an action of ours (it may be a natural or accidental event or someone else's action), then our involuntarily having played a causal role in the history of E - by, say, having conceived, built, and having been in possession of something that, unbeknownst to us, has played a causal role in the history of $E$ - cannot be enough for an ascription of responsibility.

Here we don't even need to go looking for fancy counterexamples, as Janzen's own scenario is a counterexample to his wide account of responsibility. If having conceived, built, and having been in possession of something that has, unbeknownst to us, played a causal 
role in the history of $E$ is enough to be responsible for $E$, then Bert isn't just responsible, as Janzen claims, for not framing Bart; Bert is also responsible, contrary to what Janzen claims ("Bert is not responsible for framing Bart" (9)), for the framing of Bart, as the framing of Bart is also an event such that Bert played a role in its history by devising, building, and being in possession of an object that played a causal role in the history of the framing of Bart. Similarly (and again contrary to what Janzen claims: "Jones is not responsible for shooting Smith in the counterfactual scenario in which Black intervenes" (8)), on Janzen's wide account of responsibility, Jones would be responsible for the killing of Smith in the counterfactual scenario, as Jones's facial twitch is in the causal history of the killing of Smith. This point is particularly important because, once Sally and Black have intervened, then Bert and Jones have no alternative possibilities. And if they are responsible for what happens despite not having alternative possibilities, then Janzen, in trying to defend PAP from Frankfurt's counterexample, would have himself put forward an argument against PAP. ${ }^{8}$

Summing up, Janzen's argument against my defence of Frankfurt's counterexample fails on two independent counts as both Premise $1^{*}$ and Premise $2^{*}$ are false. ${ }^{9}$

\footnotetext{
${ }^{8}$ This could be resisted by pointing out that what Janzen has in mind is a necessity rather than a sufficiency condition for responsibility (thanks to anonymous reviewers for this point): I think that Janzen's account is implausible even if conceived just as a necessary condition, but as this whole point about responsibility is not necessary to my argument I will not press it any further.

${ }^{9}$ This paper only replies to Janzen. For my own position on these and related issues regarding agency, free will and responsibility please see Di Nucci 2008, Di Nucci 2009, Di Nucci 2010a, Di Nucci 2010b, Di Nucci 2011a, Di Nucci 2011b, Di Nucci 2011c, Di Nucci 2012, Di Nucci 2013a, Di Nucci 2013b, and Di Nucci 2014.
} 


\section{References}

Alvarez, M. (2009). Actions, thought-experiments, and the 'principle of alternate possibilities'. Australasian Journal of Philosophy, 87, 61-81.

Davidson, D. (1980). Essays on Actions and Events. Oxford UP.

Di Nucci, E. (2008), Mind Out of Action. VDM Verlag.

Di Nucci, E. (2009), Simply, false', Analysis 69 (1), 69-78.

Di Nucci, E. (2010a), Refuting a Frankfurtian Objection to Frankfurt-Type Counterexamples, Ethical Theory and Moral Practice 13 (2), 207-213.

Di Nucci, E. (2010b). Rational constraints and the Simple View. Analysis 70: 481-86.

Di Nucci, E. (2011a), Frankfurt counterexample defended, Analysis 71 (1), 102-104

Di Nucci, E. (2011b), Frankfurt versus Frankfurt: a new anti-causalist dawn, Philosophical Explorations 14 (1): 1-14.

Di Nucci, E. (2011c), Automatic Actions: Challenging Causalism, Rationality Markets and Morals 2 (1): 179-200.

Di Nucci, E. (2012), Priming Effects and Free Will. International Journal of Philosophical Studies 20(5): 725-734.

Di Nucci, E. (2013a), Mindlessness. Cambridge Scholars Publishing.

Di Nucci, E. (2013b), Action, Deviance, and Guidance. Abstracta 7 (2): 41-59.

Di Nucci, E. (2014), Ethics Without Intention. Bloomsbury.

Fischer JM (1982) Responsibility and control. J Philos 79(1):24-40.

Fischer, J.M. (1999). Recent Work on Moral Responsibility. Ethics 110 93-139.

Frankfurt, H. (1969). Alternate possibilities and moral responsibility. Journal of Philosophy, $66,829-839$. 
Janzen, G. (2013). Frankfurt Cases, Alternate Possibilities, and Prior Signs. Erkenntnis 78 (5): 1037-1049.

Kane R (1985) Free will and values. SUNY series in philosophy. SUNY, Albany Kane R (1996) The significance of free will. Oxford University Press, New York Larvor, B. (2010). Frankfurt counter-example defused. Analysis, 70, 506-508.

Levy, N. \& McKenna, M. (2009). Recent Work on Free Will and Moral Responsibility. Philosophy Compass, 4, 96-133.

McKenna M (1997) Alternative possibilities and the failure of the counterexample strategy. J Soc Philos 28:71-85.

Otsuka M (1998) Incompatibilism and the avoidability of blame. Ethics 108:685-701.

Pettit, G. (2005). Moral responsibility and the ability to do otherwise. Journal of Philosophical Research, 30, 303-319.

Steward, H. (2006). 'Could have done otherwise', action sentences and anaphora. Analysis, 66, 95-101.

Widerker, D. (1995). Libertarianism and Frankfurt's attack on the principle of alternative possibilities. Philosophical Review, 104, 247-261.

Woodward, P. A. (2002). Why Frankfurt examples beg the question. Journal of Social Philosophy, 33, 540-547.

Wyma, K. (1997). Moral responsibility and leeway for action. American Philosophical Quarterly, 34, 57-70. 